\section{Chemical Height Control of Containerized Seashore Mallow}

\author{
Kimberly R. Hilgers, \\ Cynthia Haynes, and \\ William R. Graves
}

\begin{abstract}
Additional Index wORDs. Kosteletzkya virginica, native plants, herbaceous perennial, plant growth regulators, ancymidol, dikegulac sodium, paclobutrazol, chlormequat chloride, daminozide
\end{abstract}

SumMARY. The objective of this study was to determine the efficacy of plant growth regulators applied as foliar sprays on height and branching of seashore mallow (Kosteletzkya virginica). Five chemical plant growth regulators were applied: ancymidol $[15,25$, and $\left.50 \mathrm{mg} \cdot \mathrm{L}^{-1}(\mathrm{ppm})\right]$ (A-Rest; Elanco Products Co., Indianapolis), dikegulac sodium $(500,1000$, and 1500 mg. L $^{-1}$ ) (Atrimmec; PBI/Gordon Corp., Kansas City, Mo.), paclobutrazol $\left(10,20\right.$, and $\left.60 \mathrm{mg} \cdot \mathrm{L}^{-1}\right)$ (Bonzi; Uniroyal Chemical Co., Middlebury, Conn.), chlormequat chloride (CCC) $\left(750,1000\right.$, and $\left.1500 \mathrm{mg} \cdot \mathrm{L}^{-1}\right)\left(\mathrm{Cyco}^{-}\right.$ cel; Olympic Horticultural Products, Mainland, Pa.), and CCC/daminozide mixes $(1000 / 2500,1000 / 5000$, and $\left.1500 / 5000 \mathrm{mg} \cdot \mathrm{L}^{-1}\right)($ Cycocel and B-Nine; Uniroyal Chemical Co.). Ten replicate plants of each concentration were evaluated weekly for plant height and number of branches for 8 weeks. Plants that received CCC and CCC/daminozide treatments at all concentrations and paclobutrazol at $60 \mathrm{mg} \cdot \mathrm{L}^{-1}$ were $60 \%, 60 \%$, and $48 \%$ shorter than control plants and had $113 \%, 100 \%$, and $75 \%$ more branches than control plants, respectively. All concentrations of ancymidol and dikegulac sodium-treated plants were similar to control plants. Paclobutrazol was applied twice, and only the

\footnotetext{
Department of Horticulture, Iowa State University, Ames, IA 50011-1100.

Journal paper of the Iowa Agriculture and Home Economics Experiment Station, Ames, Iowa, Project No. 3603 and supported by a grant from the Perennial Plant Association. Mention of a trademark, proprietary product, or vendor does not constitute a guarantee or warrantee of the product and does not imply its approval to the exclusion of other products or vendors that also may be suitable. We gratefully acknowledge J.A. Schrader for his assistance with data analysis.
}

highest concentration was effective for height control. Chlormequat chloride at the lowest concentration was as effective as all other concentrations of CCC and CCC/daminozide.

S eashore mallow is native to marshes in the southeastern United States (Fernald, 1950). The tolerance of seashore mallow to extreme moisture conditions, salts, and various soil types, in addition to its long flowering period, make it a promising ornamental perennial (Armitage, 1997). However, trials we conducted to assess development of containerized plants in greenhouses resulted in unattractive, excessively tall shoot systems.

Several plant growth regulators (PGRs) are used commercially to restrict growth and promote branching. Performance of PGRs varies greatly by species and cultivar (Latimer et al., 1998), and therefore, efficacy and concentrations must be determined for each taxon of interest. Response of seashore mallow to PGRs has not been documented. However, other genera within Malvaceae, such as hibiscus (Hibiscus spp.), have been studied (Shanks, 1972; Wang and Gregg, 1991). Warner and Erwin (2003) used PGRs on three hibiscus species to limit stem elongation and reported mixed results. Some species responded to specific PGRs, while others did not. Our objective was to determine the efficacy of foliar application of five PGRs on height and branching of seashore mallow.

\section{Materials and methods}

Seeds of seashore mallow were acquired in the wild from salt marshes in Delaware. On 12 Jan. 2002, seeds were sown in germination substrate (Super Fine; Conrad-Fafard, Agawam, Mass.), lightly covered with vermiculite, and placed on bottom heat at 28 ${ }^{\circ} \mathrm{C}\left(82.4^{\circ} \mathrm{F}\right)$ under intermittent mist, applied for 15 s every 15 min. At $30 \%$ to $40 \%$ emergence, flats were removed from mist and irrigated with tap water once daily. Seedlings were transplanted into plastic pots [ $12.7-\mathrm{cm}$ (5 inches) diameter, $818 \mathrm{~cm}^{3}\left(49.9\right.$ inch $\left.^{3}\right)$ volume] containing soilless substrate (Sunshine LCl Professional Growing Mix; Sungrow, Bellevue, Wash.) 23 d after sowing. Plants grew in a glassglazed greenhouse for the duration of the experiment. Night and day temperatures were 20 and $25 \pm 3{ }^{\circ} \mathrm{C}$ $\left(68.0\right.$ and $\left.77.0 \pm 5.4^{\circ} \mathrm{F}\right)$, respectively. Plants were grown under natural irradiance in Ames, Iowa. An LI190SB quantum sensor (LI-COR, Lincoln, Nebr.) recorded photosynthetically active radiation $(P A R)$ hourly. Mean PAR during the middle $5 \mathrm{~h}$ of photoperiods was $653 \mu \mathrm{mol} \cdot \mathrm{m}^{-2} \cdot \mathrm{s}^{-1}$.

Ten plants were assigned randomly to each of 16 treatment groups when plants had three to four expanded true leaves and roots were visible at the edge of the substrate. Plant growth regulators were applied to runoff by using a hand-held misting bottle. The chemicals and concentrations were: ancymidol $\left(15,25\right.$, and $\left.50 \mathrm{mg} \cdot \mathrm{L}^{-1}\right)$, dikegulac sodium $(500,1000$, and $\left.1500 \mathrm{mg} \cdot \mathrm{L}^{-1}\right)$, paclobutrazol $(10,20$, and $\left.60 \mathrm{mg} \cdot \mathrm{L}^{-1}\right), \operatorname{CCC}(750,1000$, and $\left.1500 \mathrm{mg} \cdot \mathrm{L}^{-1}\right)$, and CCC/daminozide mixture $(1000 / 2500,1000 / 5000$, and $\left.1500 / 5000 \mathrm{mg} \cdot \mathrm{L}^{-1}\right)$. Distilled water was applied as a control and was used to make all solutions. Plants treated with paclobutrazol received a second application $10 \mathrm{~d}$ later per label recommendations.

Plants were supplied each day with tap water to prevent wilting. A 300 $\mathrm{mg} \cdot \mathrm{L}^{-1}$ solution made of $75 \%$ Peters Cal-Mag 15-5-15 (15N-2.2P-12.5K) and $25 \%$ Peters All Purpose $21-5-20$ $(21 \mathrm{~N}-2.2 \mathrm{P}-16.6 \mathrm{~K})$ for a total of $16.5 \mathrm{~N}-2.2 \mathrm{P}-13.5 \mathrm{~K}$ (Scotts Co, Marysville, Ohio) was applied twice at $1.7 \mathrm{~L}(0.45 \mathrm{gal})$ per pot.

Plant height was measured once weekly for 8 weeks. Height was measured as the distance between the top surface of growing substrate and the apex of the primary stem. Visual comparisons were made between control plants and treated plants. Distinct leaf color differences and flowering time were noted. The number of first-order lateral branches was counted at the end of 8 weeks.

A randomized complete-block design (SAS, 1999) was used, consisting of 16 treatment groups (five PGRs at three concentrations each and a control) with 10 replications each. Linear regression and analysis of variance were performed. Height and branch data from treated plants were compared with data from the controls by Dunnett's one-tailed $t$ test $(P \leq 0.05)$. Rate effects for height and branching were determined by using a general linear model (GLM) procedure with 
Fig. 1. Mean height $( \pm$ SD $)$ of seashore mallow measured 8 weeks after initial foliar application of plant growth regulators. Growth regulators were applied at three concentrations to 10 single-plant replications. Low, medium, and high concentrations for each chemical in units of $\mathrm{mg} \cdot \mathrm{L}^{-1}$ (ppm) were: chlormequat chloride (CCC) $(750,1000$, and 1500), CCC/daminozide mixes $(1000 / 2500$, $1000 / 5000$, and $1500 / 5000)$, paclobutrazol $(10,20$, and 60), ancymidol $(15,25$, and 50), and dikegulac sodium $(500,1000$, and 1500$)(1 \mathrm{~cm}$ $=0.39$ inch $)$.

Tukey's honestly significant difference (HSD) test for mean separation.

\section{Results and discussion}

Plants treated with all concentrations of $\mathrm{CCC}$ and $\mathrm{CCC} /$ daminozide mixtures were $60 \%$ shorter $[35 \mathrm{~cm}$ (13.8 inches) vs. $90 \mathrm{~cm}$ (35.4 inches) tall] than control plants at week 8 (Fig. 1). Paclobutrazol at $60 \mathrm{mg} \cdot \mathrm{L}^{-1}$ resulted in plants $48 \%$ shorter than controls, whereas plants treated with paclobutrazol at 10 and $20 \mathrm{mg} \cdot \mathrm{L}^{-1}$ were similar to control. Paclobutrazol was the only PGR to show a decrease in height with an increase in concentration. Ancymidol and dikegulac sodium at all concentrations were similar in height when compared to control plants $(P$ $=0.50)$. Average number of branches for plants treated with paclobutrazol, $\mathrm{CCC}$, and CCC/daminozide increased from 8 to 14,17 , and 16 branches, respectively $(P<0.01)$ (Table 1$)$. Concentration did not affect branch count. Plants treated with ancymidol and dikegulac sodium at all concentrations were similar to control plants in number of branches $(P=0.96)$ as well as leaf color and bloom time.

Fig. 2. Seashore mallow treated with plant growth regulators compared to control. (A) Control in background and plants treated with three concentrations of chlormequat chloride in foreground [left to right: 750, 1000, and $\left.1500 \mathrm{mg} \cdot \mathrm{L}^{-1}(\mathrm{ppm})\right]$. No statistical differences were found in height between rates. Note the difference in leaf color between treated plants and control. (B) Control on far right and plants treated with three concentrations of dikegulac sodium from left to right $\left(500,1000\right.$, and $\left.1500 \mathrm{mg} \cdot \mathrm{L}^{-1}\right)$. No differences in height or leaf color were found.

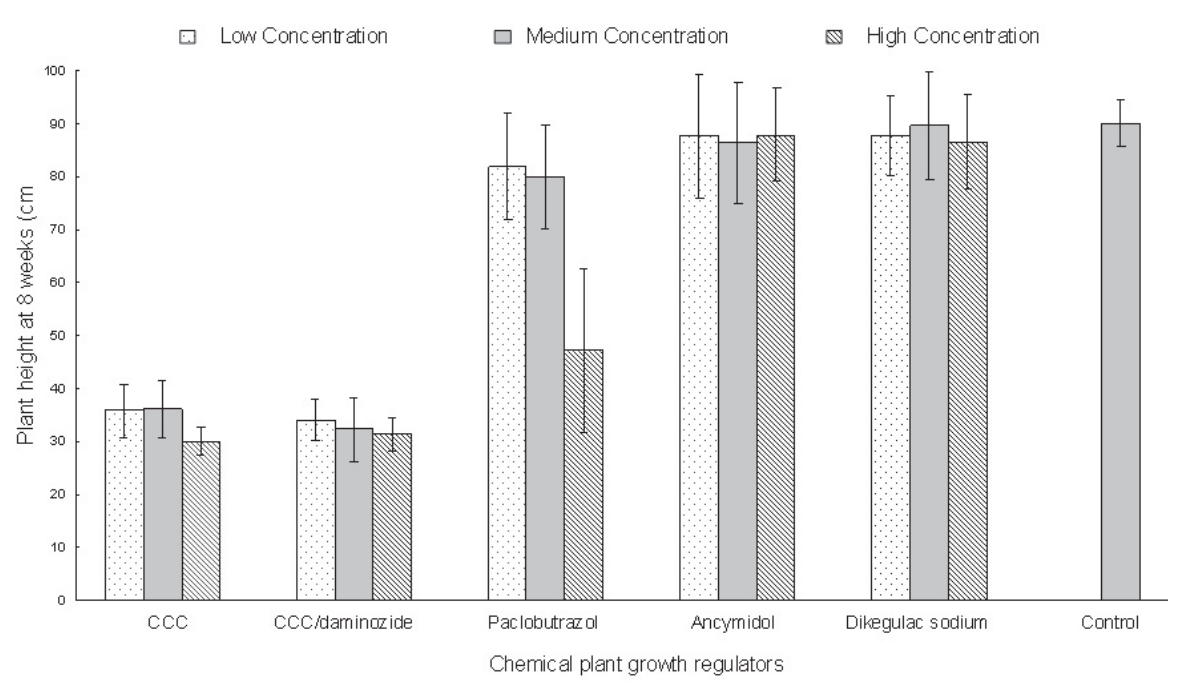

Replicates that received paclobutrazol, CCC, and CCC/daminozide treatments exhibited leaf chlorosis on $<20 \%$ of plants immediately after application. At the end of week 8, no chlorosis was visible. Treated plants also showed darker green leaves 3 weeks after application, and flowering was delayed to 14 weeks compared with 12 weeks for control plants (Fig. 2). Depending upon the chemical and concentration applied, treatment can result in phytotoxicity in the form of chlorosis and delayed flowering (Gibson and Whipker, 2003; Kim et al., 1999).

Our results are similar to previous reports on another genus within Malvaceae wherein CCC effectively limited stem elongation in hibiscus spp. (Shanks, 1972; Wang et al., 1998;

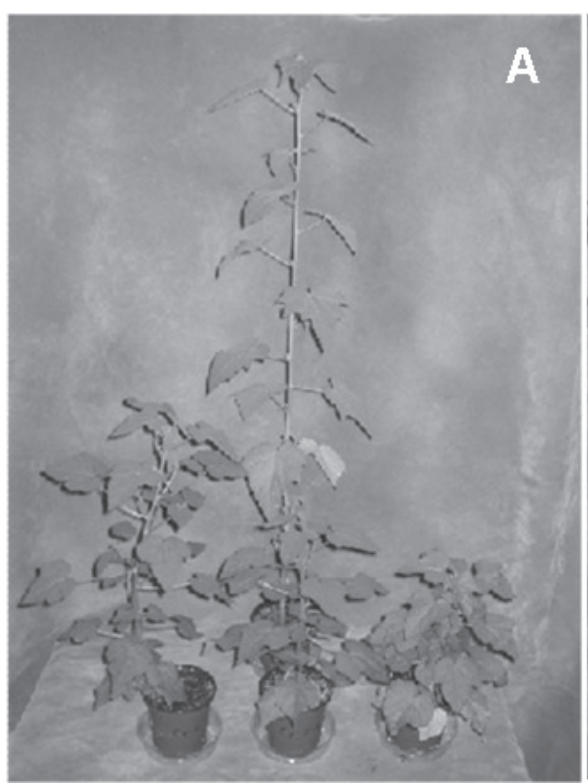

Table 1. Average number of branches measured on seashore mallow 8 weeks after being treated with plant growth regulators (PGRs). Five PGRs were applied when three to four expanded leaves were present. Results were averaged across concentrations for plant growth regulators because there were no rate effects.

\begin{tabular}{lc}
\hline Plant growth regulator & $\begin{array}{c}\text { Branches } \\
\text { (no.) }\end{array}$ \\
\hline Chlormequat chloride & $17 \mathrm{a}^{\mathrm{z}}$ \\
Chlormequat chloride & \\
$\quad$ daminozide & $16 \mathrm{a}$ \\
Paclobutrazol & $14 \mathrm{a}$ \\
Ancymidol & $9 \mathrm{~b}$ \\
Dikegulac sodium & $10 \mathrm{~b}$ \\
Control & $8 \mathrm{~b}$ \\
\hline
\end{tabular}

${ }^{2}$ Number of branches followed by the same letter are not significantly different (Tukey's HSD, $P=0.05$ ).

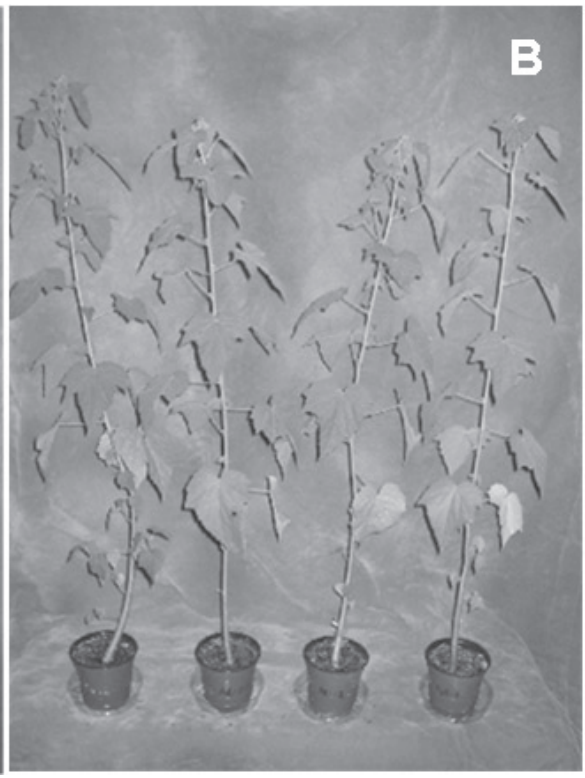


Warner and Erwin, 2003). Warner and Erwin (2003) concluded that multiple applications of paclobutrazol were needed to control stem elongation in hibiscus species. Our research indicated that two applications of paclobutrazol were also effective for control height of seashore mallow.

Although paclobutrazol controlled height and increased branching, its label recommends multiple applications. The CCC/daminozide mix was also effective, but required the combination of two chemicals in higher concentrations than the most effective concentration of CCC alone. A single foliar application of CCC at $750 \mathrm{mg} \cdot \mathrm{L}^{-1}$ to seashore mallow when three to four expanded leaves are present would be most logical when considering material costs and increased labor for multiple applications. However, since no rate effects were noticed with CCC in this study, it is possible that a lower concentration may prove effective. Application at other growth stages may alter effectiveness as would the application method.

This information is valuable for growers interested in adding a durable and attractive native perennial to their product line. Further research should be conducted to determine if drench application of PGRs affects height or branching of seashore mallow.

\section{Literature cited}

Armitage, A.M. 1997. Herbaceous perennial plants: A treatise on their identification, culture, and garden attributes. 2nd ed. Stipes, Champaign, Ill.

Fernald, M.L. 1950. Gray's manual of botany. 8th ed. Amer. Book Co., New York.

Gibson, J.L. and B.E. Whipker. 2003. Efficacy of plant growth regulators on the growth of vigorous Osteospermum cultivars. HortTechnology 13:132-135.

Kim, S.-H., A.A. De Hertogh, and P.V. Nelson. 1999. Effects of plant growth regulators applied as sprays or media drenches on forcing of Dutch-grown bleeding heart as a flowering potted plant. Hort Technology 9:630-635.

Latimer, J.G., P. Lewis, and P.A. Thomas. 1998. An evaluation of growth control on nine greenhouse-grown perennial bedding plants. Greenhouse Prod. News 8(11):30-32.

SAS Institute. 1999. SAS/STAT statistical analysis system manual (V. 8). SAS Inst., Cary, N.C.

Shanks, J.B. 1972. Chemical control of growth and flowering in hibiscus. HortScience 7:574.

Wang, S., R.D. Heins, W. Carlson, and A. Cameron. 1998. Forcing perennials: Hibiscus moschentos 'Disco Belle Mixed'. Greenhouse Grower 16(2):29-32.

Wang, Y. and L.L. Gregg. 1991. Modification of hibiscus growth by treating unrooted cuttings and potted plants with uniconizole or paclobutrazol. J. Plant Growth Regulat. 10:47-51.

Warner, R.M. and J. E. Erwin. 2003. Effect of plant growth retardants on stem elongation of hibiscus species. HortTechnology 13:293-296. 